\title{
PARQUE DA CIDADE DE SÃO JOSÉ DOS CAMPOS: UM ESTUDO DE CASO
}

\author{
THE PARK OF THE CITY IN SÃO JOSÉ DOS CAMPOS: A CASE STUDY
}

\section{JORGE, Vinie Pedra}

Arquiteta, urbanista e mestranda em Urbanismo, pela Pontifícia Universidade Católica de Campinas - PUCCamp.

E-mail:v_pedra@yahoo.com.br

\section{RESUMO}

O presente trabalho tem como proposta apresentar um estudo sobre o Parque da Cidade de São José dos Campos. Sua história, e suas relações com a memória local criaram uma identidade própria no sistema de espaços livres públicos do município. Originalmente projetado por Burle Marx como espaço de entorno das instalações da Tecelagem Parahyba foi apropriado mais tarde pela população do bairro, passando da condição de espaço privado a público e assumindo a identidade de parque da cidade. Propõe-se discutir os porquês de um parque inicialmente de propriedade privada ter estendido seus usos à esfera de vida pública e também compreender seu papel no contexto paisagístico da cidade.

Palavras-chave: São José dos Campos, Burle Marx, industrialização, parques urbanos, apropriação, espaço público.

\begin{abstract}
The present work proposes to present a study about the Park of the City of São José dos Campos. Its history and its relations with the local memory have created its own identity in the system of public spaces of the district. Originally designed by Burle Marx as a space surrounding the textile industry Tecelagem Parahyba, the park has been appropriated by the population of the area, going from the condition of private to public space and assuming an identity of public park of the city. It is proposed to discuss the reasons why a park initially part of a private property has extended its uses to the sphere of public life and also to understand its role in the context of the landscape architecture in the city.
\end{abstract}

Key words: São José dos Campos, Burle Marx, industrialization, urban parks, appropriation, public spaces.

\section{O surgimento de um parque público}

Para uma melhor compreensão do sistema de objetos que formam a paisagem da cidade de São José dos Campos é necessário um maior entendimento dos vários momentos de desenvolvimento pelos quais esta cidade passou e conseqüentemente modificações em sua paisagem?

O café foi o maior responsável pelo desenvolvimento da região durante praticamente 100 anos - de 1830 até meados de 1930 - modificando a paisagem do Vale para sempre ${ }^{2}$. Ao final dos anos 20 observa-se um grande crescimento na pecuária leiteira da região constituindo mais tarde a bacia Leiteira do Vale do Paraíba ${ }^{3}$. Apesar de a pecuária leiteira não ter sido uma atividade de grande relevância econômica tanto quanto o café para o município foi aquela que lhe substituiu, entretanto com menor densidade e importância como vemos em Santos (2002).

Com o surgimento da indústria na região do Vale do Paraíba há um crescimento econômico progressivo que leva ao um aumento significativo da população e a uma modificação da paisagem urbana joseense. Mudanças na vida social, econômica e cultural do município são percebidas e com a instalação de outras empresas a partir de meados de 1930 vem a modificar drasticamente bairros completos, trazendo emprego, tecnologia, e crescimento para a cidade. 
O Vale, que provinha de um histórico de produção estritamente agrícola de cafeicultura tinha vários aspectos a seu favor: localização estratégica entre as capitais do Rio de Janeiro e São Paulo - que já eram os principais centros de distribuição de consumo do país - muitas terras provenientes das antigas fazendas de café à disposição de investimento, e mão de obra - que se encontrava desempregada em virtude da queda da produção cafeeira. Desta forma, a região do Vale participa, desde o inicio, do processo de industrialização desde as últimas décadas do século XIX - quando o mesmo apesar de não ser o único grande produtor de café da região era a região mais urbanizada do interior - até o surgimento de industrias de alta tecnologia como a Embraer, em 1969.

Parte deste importante desenvolvimento econômico e urbano do município se dá mais especificamente no bairro de Santana, porta de entrada da cidade na região norte que tinha por volta dos anos de 1920 um notável desenvolvimento e dinâmica urbana bastante intensa": "O comércio de outro lado se apresentava de modo bastante desenvolvido e diversificado, fruto talvez da localização do bairro como ponto de 'passagem forçada dos habitantes de Buquira, Patrocínio, S. Francisco Xavier, e sul de Minas, sem contar os innumeros bairros que o município tem além - Parahyba', esse comércio contava com treze casas de secos e molhados, quatro lojas de tecidos, um açougue, um bar e bilhar e dois salões de barbeiro." Além do intenso comercio o bairro possuía intensa vida cultural, religiosa e folclórica, com a fundação de clubes literários, e grupos de dramaturgia bastante atuantes na comunidade. Em local privilegiado, tanto para o desenvolvimento do comércio como para a implantação das primeiras grandes indústrias têxteis o bairro recebe a implantação de indústrias como a Rhodosá de Rayon - Rhodia (1946) a Tecelagem Parahyba fundada em 1926 (Figura 1).

Com a instalação de industrias de médio e grande porte e o crescimento do bairro, a vida recreativa e de lazer da população local acontece ora de maneira privada - em suas residências ou residências de vizinhos, ora nas ruas de maneira pública. Na ausência de espaços livres públicos como praças e parques, a família Gomes proprietária da Tecelagem Parahyba cede suas instalações para festejos populares e não só o operariado como a população do bairro participa de certa forma da vida privada desta família (Figura 2).

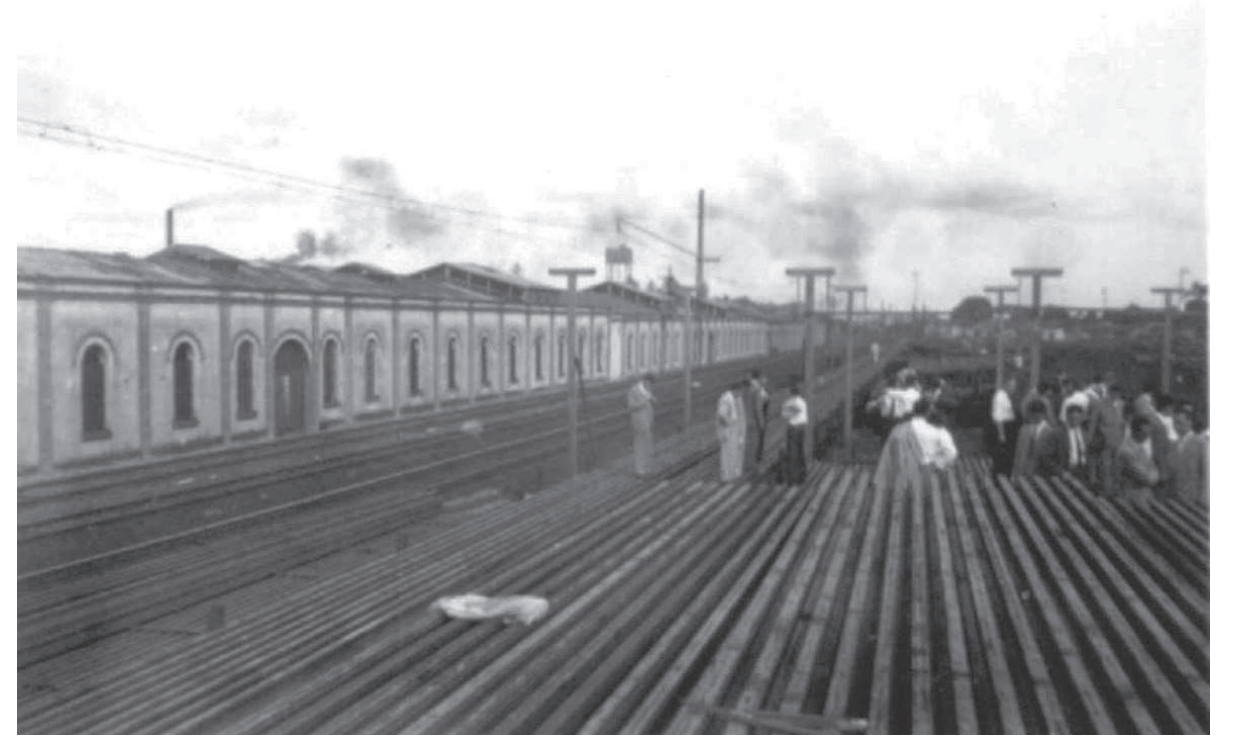

Figura 1: A construção da Tecelagem Parahyba Fonte: Arquivo Histórico da Fundação Cassiano Ricardo

A partir da abertura da propriedade da família Gomes à participação do operariado e à população do bairro há com o passar dos anos uma a apropriação publica de seus jardins particulares de forma que mais tarde juntamente com toda a área da antiga Tecelagem, tornam-se o Parque da Cidade de São José dos Campos. 


\section{O parque da cidade}

Com o movimento de apropriação iniciado em meados de 1940 alternam-se festas da alta sociedade paulista e festas populares em seus jardins. (Figura 3) $\bigcirc$ futuro parque torna-se espectador da ascensão da família nos meios políticos e econômicos deste país, e participante ativo das manifestações sociais ocorridas no bairro que o abriga. Há ainda a presença constante de crianças da própria família, bem como, os filhos de operários da fabrica e de moradores do bairro que conviviam principalmente no período de férias escolares quando a Colônia de Férias da Tecelagem abria suas portas.

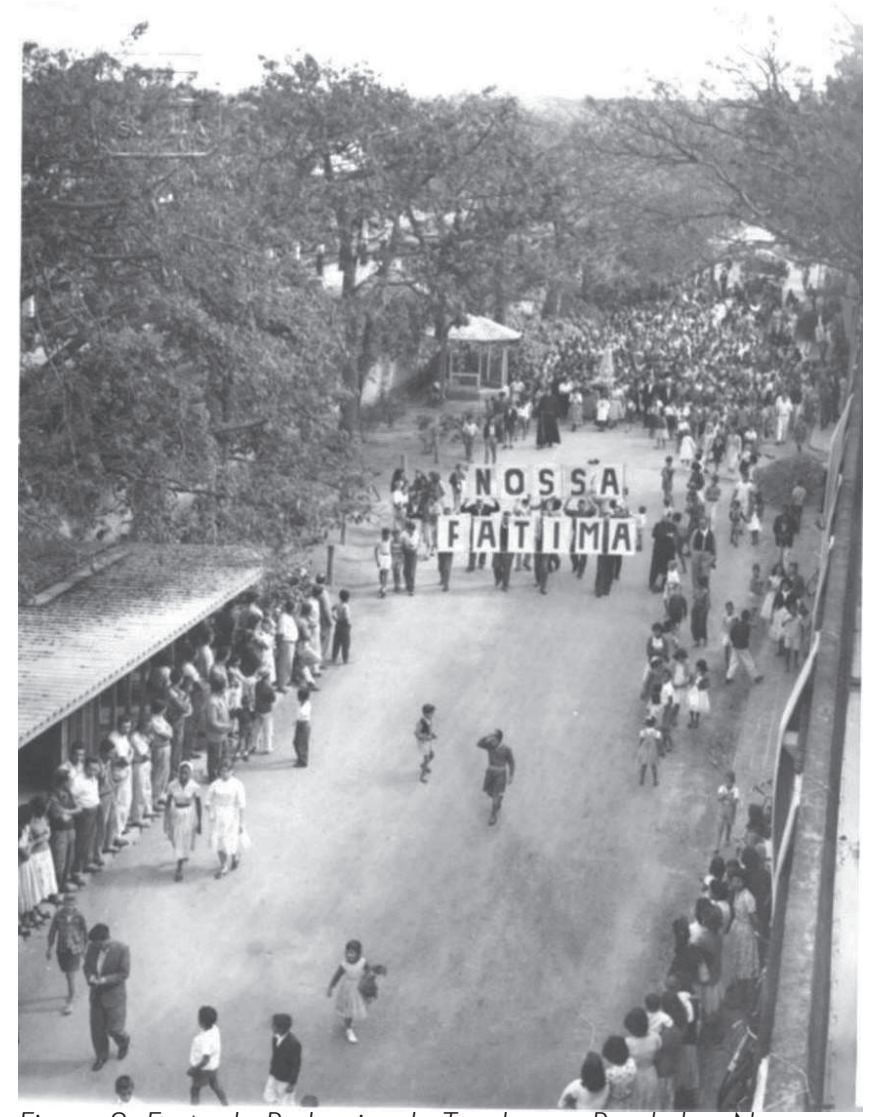

Figura 2: Festa da Padroeira da Tecelagem Parahyba: Nossa Senhora de Fátima

Fonte: Arquivo Histórico da Fundação Cassiano Ricardo

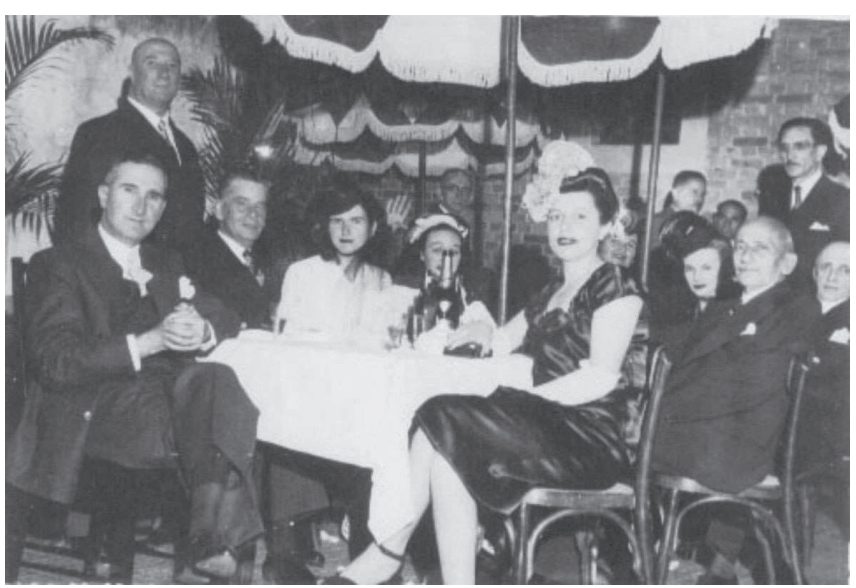

Figura 3: Festas da sociedade paulista nos jardins da residência de Olivo Gomes

Fonte: Arquivo Histórico da Fundação Cassiano Ricardo
Até então havia a antiga casa da família (atual Museu do Folclore), a Fazenda Santana do Rio Abaixo também pertencente à família e a Tecelagem. Mais tarde entre as décadas de 1950 e 1960 com a construção da nova residência de Olivo Gomes (19511957) - projeto do arquiteto Italiano Rino Levi e dos Jardins que a abrigavam (1961) por Burle Marx há uma unidade maior na propriedade (Figura 4).

Com a obra da residência da família Gomes uma série de novos projetos se sucede, entre eles: o projeto para o complexo industrial da Tecelagem Parahyba que abrange: o mercado e o Conjunto Residencial para Operários (1951 e 1953) - com creche, jardim da infância, centro de saúde e igreja - o galpão para equipamentos (1953), o hangar para aviões (1953) e posto de gasolina (1953), o estádio de futebol (1957) e a usina de leite Parahyba (1963)5. (Figura 5).

Apesar de sua existência e utilização pela população desde os anos de 1940 o parque foi apenas reconhecido como tal em 1996 quando oficialmente aberto para a população e nomeado Parque Roberto Burle Marx em homenagem ao idealizador dos jardins e de todo o paisagismo do parque. Apesar de sua importância, foram necessárias mais de sete décadas para que o Parque fosse considerado patrimônio arquitetônico e ambiental pelo Comphac ${ }^{6}$, sendo que em julho do mesmo ano (2004) o parque, que já era considerado público pela população, tornou-se "legalmente público" e pertencente à Prefeitura da cidade?

Desde a desativação da área da tecelagem e de ter se tornado oficialmente um parque público o Parque da Cidade de São José dos Campos recebe visitação diária de mais 

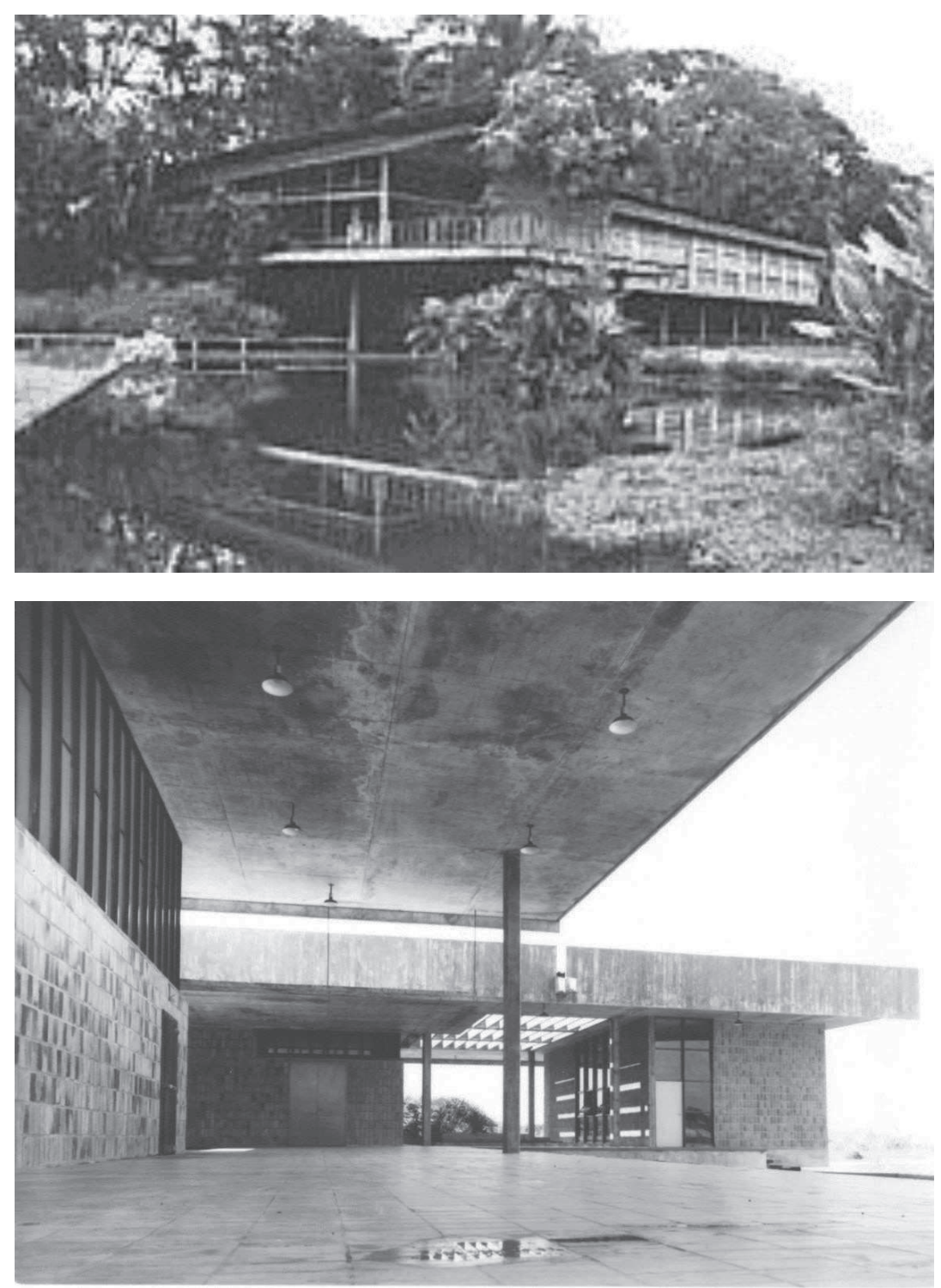

Figura 4: Residência Olivo Gomes - Projeto de Rino Levi (1951-1957)

Fonte: Arquivo Histórico da

Fundação Cassiano Ricardo
Figura 5: Usina de leite Parahyba - Rino Levi (1963)

Fonte: Arquivo Histórico da Fundação Cassiano Ricardo

de 500 pessoas. Nos finais de semana tal número cresce para cerca de 3.000 pessoas que procuram a tranqüilidade de suas instalações e do contato com a natureza. No local atualmente existem órgãos governamentais que utilizam as antigas instalações da tecelagem como sede. Dentre eles, a Fundação Cassiano Ricardo responsável pela documentação do patrimônio histórico do município, e algumas secretarias como a Secretaria de Meio Ambiente e a Secretaria de Esportes e Lazer.

O Parque atualmente abriga o Museu do Folclore, onde funcionava a antiga residência da família Gomes, a residência Olivo Gomes projetada pelo Arquiteto Rino Levi e a Usina de Leite do mesmo arquiteto. Além disso, a população pode usufruir os lagos, anfiteatro, ilha artificial, trilhas para caminhadas, animais e aves diversos. Uma pequena parte da tecelagem ainda funciona. Nada comparado, entretanto, com suas atividades intensas nas décadas de 1930 a 1970. Funcionam ainda em suas instalações órgãos governamentais como a Fundação Cultural Cassiano Ricardo e o Comphac.

Localizado no bairro de Santana a aproximadamente $10 \mathrm{~km}$ do centro da cidade Observam-se características de um parque de uso desportivo e de apreciação da natureza com a possibilidade de convívio com animais silvestres como pássaros e capivaras. Por ser o único parque urbano com tal porte ${ }^{8}$ e por estar localizado em um bairro majoritariamente industrial, o Parque acaba sendo uma preocupação para a administração pública no que concerne à violência urbana e 
sua manutenção. A prefeitura - órgão responsável pela administração do parque - fecha as portas do parque às 19 horas todos os dias a fim de evitar ações de depredação e vandalismo do patrimônio histórico existente em sua área.

Atualmente, 62,62\% da área territorial de São Jose dos Campos é considerada como Área de Proteção Ambiental. O Parque da Cidade (516.000 m²), o Parque Santos Dumont $\left(46.000 \mathrm{~m}^{2}\right.$ ), - Banhado (5 milhões de $\mathrm{m}^{2}$ ), além da Reserva Ecológica "Augusto Ruschi" (Horto Florestal) localizada a dois $\mathrm{km}$ do perímetro urbano constituem esta porcentagem.

No sistema de espaços livres públicos da cidade de São José dos Campos o Parque da Cidade é considerado não apenas por sua importância histórica para o bairro, bem como por sua escala em relação à cidade, sendo este o maior parque público urbano do município. É importante perceber sua importância para a arquitetura e paisagismo brasileiros, bem como compreender o processo de apropriação espontânea que sofreu transformando-o em um parque público. Tanto podemos usá-lo como referência urbana no bairro em que se encontra inserido, como exemplo histórico de apropriação de espaço público. Resta-nos identificar características neste espaço estudado que o tornaram interessante ao uso publico e à identificação dos moradores com o lugar.

\section{Notas:}

(1) Segundo Santos (2002), a urbanização na cidade de São José dos Campos é oriunda dos sistemas de produção e dos vários momentos socioeconômicos que a cidade participa, sendo estes: o café, a doença e a indústria.

(2) Por causa da destruição causada pela cafeicultura hoje vemos, na região antes coberta por cafezais, os chamados "morros carecas" nos quais, segundo agricultores da região, nada que se planta "vinga".

(3) Por volta de 1960 destacam-se as atividades da Leite Parahyba do grupo Tecelagem Parahyba.

(4) Almanaque de São José dos Campos de 1922 apud SANTOS, Emmanuel (2002).

(5) SERAPIÃO, Fernando Rino Levi: o racionalista dos trópicos. Revista Projeto Design, n. 262, 2001.

(6) Conselho Municipal de Preservação do Patrimônio Histórico, Artístico, Paisagístico e Cultural do Município de São José dos Campos.

(7) Lei n. 6493, publicada em edital no dia 05 de janeiro de 2004.

(8) A cidade possui um outro parque urbano localizado na Vila Adyana - um bairro central de São José dos Campos - chamado Parque Santos Dumont. Criado em 1971, o parque antes funcionava como o Sanatório Ezra, que tinha como especialidade o tratamento de tuberculose. Com 46.346,50 m², o parque possui: lago com criação de peixes e aves, pista de Cooper, aparelhos de ginástica, quiosques equipados com churrasqueiras, além de duas escolas de educação infantil com playground para crianças de até 10 anos.

\section{Bibliografia}

BARTALINI, Wladimir; LIMA, Catharina Pinheiro C. S.; PALLAMIN, Vera. Abrindo espaço na metrópole. Projetos para espaços públicos no centro de São Paulo. Disponível em: <http://www.etsav.upc.es/urbpersp/num06/art06-3.pdf>. Acesso em: 2004.

OLIVEIRA, José Oswaldo Reis et al. Sant'anna, São José dos Campos: Evolução histórica e diretrizes urbanas. 1999. Série Planos Diretores da Região do Vale do Paraíba, Mantiqueira e Litoral Norte, São José dos Campos.

QUEIROGA, Eugenio Fernandes. Praças e pracialidades em design: Da visualidade da paisagem à visibilidade dos lugares. I SEMINÁRIO DE SEMIÓTICA APLICADA AO DESIGN, 2003, Rio de Janeiro. Anais... Rio de Janeiro: PUCRio, 2003.

RICCl, Fabio. Origens e desenvolvimento da indústria têxtil no Vale do Paraíba paulista. 2002. 24p. Resumo de Tese (Doutorado) - Faculdade de Filosofia, Letras e Ciências Humanas da Universidade de São Paulo, São Paulo, 2002.

128 SANTOS, Ademir Pereira. Industrialização e arquitetura industrial de São José dos Campos.In: I ENCONTRO EM PATRIMÔNIO INDUSTRIAL, 2004, Campinas. Anais... Campinas: Unicamp, 2004.

SANTOS, Emmanuel Antônio. As paisagens do plano e os planos da paisagem: Da paisagem no planejamento ao planejamento com a paisagem. 2002. 206p. Tese (Doutorado) - Faculdade de Arquitetura e Urbanismo, Universidade de São Paulo, São Paulo, 2002. 